\title{
Case of Metastasis of Medullary Carcinoma Thyroid to Brain.
}

\author{
Duri Mateen', M.B., Iqbal Lone ${ }^{2}$, M.D., Tazeen Jeelani', M.B., Naheena', M.B
}

${ }^{2}$ Associate Professor, 'P.Gs., Department of Pathology, SKIMS, Soura

CASE : 57 year old female with history of headache and seizures for 3 months. Radiology revealed intraventricular ICSOL. This patient had history of hemithyroidectomy 10 years back and that was reported as follicular adenoma. Crush Biopsy received was reported as metastatic deposits

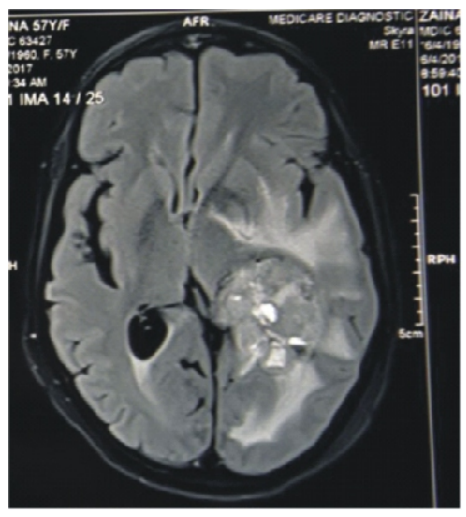

Figure 1- MRI showing the contrast enhancing lesion abutting the 4 th ventricle

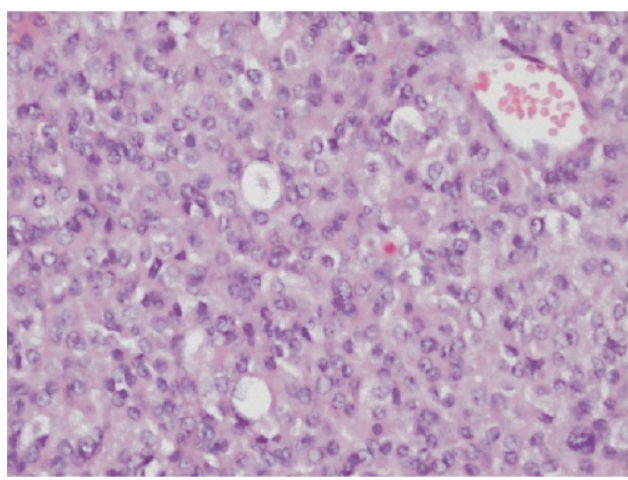

Figure 3 Nests of nuroendocrine cells with plasmacytoid features. $\mathrm{H}$ and $\mathrm{E}$ X 400

Correspondence

Dr. lqbal Lone, M.D.

Associate Professor, Department of Pathology,

SKIMS, Srinagar

Email id-mohdiqballone@yahoo.com of neuroendocrine carcinoma.HPE showed tumor cells arranged in nests with abundant vascularity. Salt and pepper chromatin was also present and was reported as metastatic deposits of Medullary carcinoma of thyroid.

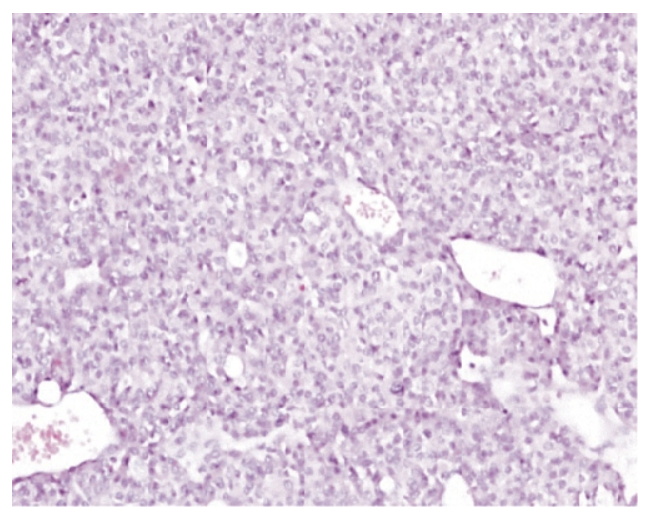

Figure 2 Nests of nuroendocrine cells H and E X 100

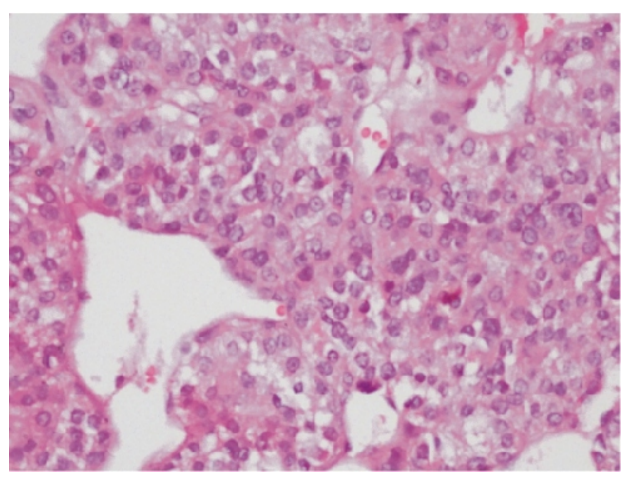

Figure 4 Nests of nuroendocrine cells and amyloid deposits $\mathrm{H}$ and $\mathrm{E}$ X 00 